Discussion Paper No. 01-27

\title{
Rejecting Capital-Skill Complementarity at all Costs
}

\author{
Manuel Frondel and Christoph M. Schmidt
}

Download this ZEW Discussion Papers from our ftp server:

ftp://ftp.zew.de/pub/zew-docs/dp/dp0127.pdf

Die Discussion Papers dienen einer möglichst schnellen Verbreitung von neueren Forschungsarbeiten des ZEW. Die Beiträge liegen in alleiniger Verantwortung der Autoren und stellen nicht notwendigerweise die Meinung des ZEW dar.

Discussion Papers are intended to make results of ZEW research promptly available to other economists in order to encourage discussion and suggestions for revisions. The authors are solely responsible for the contents which do not necessarily represent the opinion of the ZEW. 


\title{
Rejecting Capital-Skill Complementarity at all Costs
}

\author{
Manuel Frondel and Christoph M. Schmidt
}

Centre for European Economic Research, Mannheim, and

University of Heidelberg, Department of Economics

April 2001

Abstract. Any serious empirical study of factor substitutability has to allow the data to display complementarity as well as substitutability. The standard approach reflecting this idea is a translog specification - this is also the approach used by numerous studies analyzing the relative capital-skill complementarity hypothesis formulated by GRILICHES (1969). According to this hypothesis, the degree of substitutability between skilled labor and capital is lower than that for unskilled labor and capital. Yet, the results of empirical studies investigating this hypothesis are controversial. This paper offers a straightforward explanation: Using a translog approach reduces the issue of factor substitutability or complementarity to a question of cost shares. Our review of translog studies mentioned in HAMERMESH's (1993) summary on the demand for heterogeneous labor demonstrates that this argument is empirically relevant - all these studies can be reconciled with each other on the basis of the cost-share argument.

JEL classification: C3, D2.

Key words: Substitutability, Translog Cost Function.

Correspondence: Christoph M. Schmidt, Department of Economics, University of Heidelberg, Grabengasse 14, D-69117 Heidelberg, Phone: +49-6621-542955, E-mail: Schmidt@uni-hd.de. 
Non-technical Summary. Most economists would agree that any serious empirical study of factor substitutability has to allow the data to display complementarity as well as substitutability. The standard approach reflecting this idea is a translog specification - this is also the approach used by numerous studies analyzing the relative capitalskill complementarity hypothesis formulated by GRILICHES (1969). According to this hypothesis, the degree of substitutability between skilled labor and capital is lower than that for unskilled labor and capital. Yet, the results of empirical studies investigating this hypothesis are controversial: While the study by BERGSTRÖM and PANAS (1992) supports relative capital-skill complementarity and BERNDT and CHRISTENSEN (1974) even find absolute complementarity of capital and high-skilled labor, both relative and absolute complementarity is rejected by the results in BERNDT and MORRISON (1979). This paper offers a straightforward explanation: Using a translog approach reduces the issue of factor substitutability or complementarity to a question of cost shares. Specifically, it is the cost share of capital which represents the benchmark for both the estimates of capital-price elasticities of low- and high-skilled labor: Estimates of these elasticities scatter around the cost share of capital more or less due to chance. Whether or not capital-skill complementarity is estimated to hold in an empirical study is ultimately a matter of both chance and the cost shares of high- and low-skilled labor. Our review of translog studies mentioned in HAMERMESH's (1993) summary on studies of the demand for heterogeneous labor demonstrates that our cost-share argument is empirically relevant. This study's firm conclusion is that, in static translog studies, capital-price elasticities for both kinds of labor are mainly the result of the corresponding cost share of capital. A somewhat pessimistic message accompanies our straightforward cost-share argument: Static translog approaches are not as flexible as one might hope. Apparently, even three decades after GRILICHES' original insight, we know very little about the consequences for skilled and unskilled workers that might result from shifts in the price of physical capital. In particular, it is far from clear what effects current advances in technology might have for workers of either skill. Without further evidence, all too daring conclusions on the fate of the unskilled in the "new economy" should be avoided. 


\section{Introduction}

In a seminal note, GRILICHES (1969:465) investigates the hypothesis "that 'skill' or 'education' is more complementary with physical capital than unskilled or 'raw' labor". This is described by GRILICHES as (relative) capital-skill complementarity, henceforth CSChypothesis. With respect to the consequences for skilled and unskilled workers that might result from shifts in the price of physical capital, GRILICHES' prominent hypothesis is still relevant in these days of the "new economy": The CSC-hypothesis would holding output constant in the thought experiment - predict current structural change to be in favor of skilled workers, and to the disadvantage of unskilled workers.

In terms of Allen's partial elasticities of substitution (AES), the CSC-hypothesis can be expressed by the inequality

$$
\mathrm{AES}_{H K}<\mathrm{AES}_{L K}
$$

where $K$ is capital, and $H$ and $L$ denote high-skilled and low-skilled labor, respectively. For relative capital-skill complementarity to hold, $\mathrm{AES}_{H K}$ does not need to be negative. But, if $\mathrm{AES}_{H K}<0$, capital and skilled labor are even absolute complements, irrespective of whether or not inequality (1) holds. In terms of the cross-price elasticities $\eta_{x_{i} p_{j}}$ of two factors $i$ and $j$, which are related to AES by

$$
\mathrm{AES}_{i j}=\frac{1}{s_{j}} \cdot \eta_{x_{i} p_{j}} \quad(i \neq j)
$$

with $s_{j}$ denoting the cost share of factor $j$, relative capital-skill complementarity demands

$$
\eta_{H p_{K}}<\eta_{L p_{K}}
$$

According to the CSC-hypothesis, the capital-price elasticity $\eta_{H p_{K}}$ of high-skilled labor should be lower than $\eta_{L p_{K}}$, the capital-price elasticity of low-skilled labor.

Since GRILICHES' note a large number of studies have addressed the issue of capitalskill complementarity. While BERNDT and CHRISTENSEN (1974) and BERNDT and MORRISON (1979) are earlier contributions, more recent examples are BERGSTRÖM and PANAS 
(1992), FITZROY and FUNKE (1998), and BELLMANN et al. (1999) (for a comprehensive survey, see HAMERMESH 1993). Apart from FITZROY and FUNKE (1998), all other studies mentioned use static translog cost function specifications. This is the typical approach reflecting the idea that any serious empirical study of factor substitutability has to allow the data to display complementarity as well as substitutability (see SoLOW 1987:605). This approach is also employed by two out of every three and, hence, the overwhelming majority of studies summarized by HAMERMESH (1993:111) on the issue of the demand for heterogeneous labor.

Yet, with respect to the question of capital-skill complementarity, the empirical results of those studies are contradictory. While for example the study by BERGSTRÖM and PANAS (1992) supports relative capital-skill complementarity and BERNDT and CHRISTENSEN (1974) even find absolute complementarity of capital and high-skilled labor, both relative and absolute complementarity is rejected by the results in BERNDT and MORRISON (1979). Despite considerable further effort being expended upon attempting to resolve the question of relative and absolute capital-skill complementarity, this issue has remained controversial ever since.

This paper offers a straightforward explanation for the observed discrepancies: Using a static translog approach tends to reduce the issue of factor substitutability to a question of cost shares. Specifically, the magnitudes of the cost shares of capital, lowand high-skilled labor are of paramount importance for the signs of both the capitalprice elasticity of low- and of high-skilled labor. By contrast, elasticities meant to capture curvature of production isoquants are relegated to be of only minor importance. In any translog study, estimated cross-price elasticities $\eta_{x_{i} p_{j}}$ of any factor $i$ with respect to the price $p_{j}$ of another factor $j$ are predominantly determined by the cost share of that factor $j$ whose price is changing. Moreover, the estimate of the cross-price elasticity $\eta_{x_{i} p_{j}}$ tends to be the closer to the cost share $s_{j}$ of factor $j$, the higher is the cost share of factor $i$.

Typically, empirical cost shares of high-skilled labor are much lower than those of low-skilled labor. According to our cost-share argument, capital-price elasticities of low-skilled labor should thus be closer to the cost share of capital than capital-price 
elasticities of high-skilled labor. For this reason alone, it may happen that estimates of $\eta_{H p_{K}}$ are much lower than those of $\eta_{L p_{K}}$, apparently confirming relative or even absolute capital-skill complementarity. Yet, as a result of a different constellation of cost shares, it may also happen that estimates of $\eta_{H p_{K}}$ are much higher than those of $\eta_{L p_{K}}$, which would seem to contradict GRILICHES' (1969) hypothesis. In any case, translog-estimates of $\eta_{L p_{K}}$ and $\eta_{H p_{K}}$ both tend to reflect the cost share $s_{K}$ of capital closely, making the attempt to address the CSC hypothesis on the basis of the single most used empirical specification rather moot.

Section 2 deals with the relationship of cost shares and cross-price elasticities within dual translog approaches. In Section 3, all accessible translog studies cited by HAMERMESH (1993) are summarized by two figures, while Section 4 offers a detailed review of these studies. Section 5 concludes.

\section{Cross-Price Elasticities Within Translog Studies}

The overwhelming majority of studies analyzing the issue of factor substitutability employs the classical dual translog approach (for example, see APOSTOLAKIS' (1990) review on the capital-energy controversy or HAMERMESH's and GRANT's (1979) summary of the literature on skill substitution). In translog studies, it is typically assumed that in manufacturing there exists a homothetic, twice differentiable aggregate translog cost function of the form (see TAKAYAMA 1985:148)

$$
\ln C\left(p_{1}, \ldots, p_{I}, Y\right)=\beta_{0}+\beta_{Y} \ln Y+\sum_{i=1}^{I} \beta_{i} \ln p_{i}+\frac{1}{2} \sum_{i, j=1}^{I, I} \beta_{i j} \ln p_{i} \ln p_{j},
$$

where $p_{i}$ denotes the price of input $i$ and $Y$ aggregate output. Symmetry of $\beta_{i j}$ is imposed a priori. If all second-order translog parameters $\beta_{i j}$ are equal to zero, expression (4) specializes to the well-known COBB-DOUGLAS cost function. Linear homogeneity in prices, an inherent feature of any cost function, requires

$$
\sum_{i=1}^{I} \beta_{i}=1 \quad \text { and } \quad \sum_{i=1}^{I} \beta_{i j}=0 \quad \text { for } j=1, \ldots, I .
$$


Applying SHEPHARD's Lemma, $x_{i}=\frac{\partial C}{\partial p_{i}}$, and differentiating (4) logarithmically, one can derive a linear expression of the share of overall cost attributable to each factor $i$,

$$
s_{i}=\frac{x_{i} p_{i}}{C}=\frac{\partial \ln C}{\partial \ln p_{i}}=\beta_{i}+\sum_{j=1}^{I} \beta_{i j} \ln p_{j} .
$$

In the further analysis, this paper focuses on cross-price elasticities, specifically on $\eta_{L p_{K}}$ and $\eta_{H p_{K}}$, the capital-price elasticities of low- and high-skilled labor. Our focus deliberately contrasts the empirical studies in the literature which typically report ALLEN elasticities of substitution (AES), the most prominent measures of substitution. However, already BLACKORBY and RUSSELL (1989:883) criticize AES to have no meaning as a quantitative measure and, qualitatively, to add no more information to that contained in the cross-price elasticity.

The expression for the cross-price elasticity $\eta_{x_{i} p_{j}}$ for translog cost functions of the form (4) reads

$$
\eta_{x_{i} p_{j}}=\frac{\beta_{i j}}{s_{i}}+s_{j} \quad \text { for } \quad i \neq j .
$$

Obviously, the cost shares $s_{i}$ and $s_{j}$ of both factors $i$ and $j$ affect the cross-price elasticity $\eta_{x_{i} p_{j}}$. From a closer inspection of expression (7), it is to be expected that, in general, the cross-price elasticity $\eta_{x_{i} p_{j}}$ will be close to the cost share of factor $j$ if factor $i$ 's cost share is large relative to the second-order coefficient $\beta_{i j}$. If the translog cost function (4) specializes to the Совв-DougLAs function $\left(\beta_{i j}=0\right.$ for all $\left.i, j\right), \eta_{x_{i} p_{j}}$ is even equal to the cost share of factor $j$. Moreover, estimates of $\eta_{x_{i} p_{j}}$ generally should tend to be the closer to the cost share $s_{j}$, the larger is the cost share $s_{i}$. Then, expression (7) is clearly dominated by the cost share $s_{j}$ of factor $j .^{1}$ The economic intuition behind this reasoning is: The larger the cost share $s_{i}$ of factor $i$ already is, the harder it is to substitute $i$ for a factor $j$ whose price is increasing, and input reactions of $i$ depend upon the "importance" of factor $j$ measured in terms of its cost share $s_{j}$.

\footnotetext{
${ }^{1}$ The focus on cross-price elasticities rather than on AES has the advantage that it is relatively transparent under which conditions cost shares of the factor capital are a close approximation to both elasticities $\eta_{L p_{K}}$ and $\eta_{H p_{K}}$. This will be difficult with a focus on AES, since in $\mathrm{AES}_{i j}=\frac{\beta_{i j}}{s_{i} s_{j}}+1(i \neq j)$ products of cost shares are involved in the denominator.
} 


\section{Summary of the Empirical Evidence}

This section analyzes all accessible static translog studies of HAMERMESH's (1993) comprehensive review on the issue of the demand for heterogeneous labor. In static translog approaches, as theoreticaly motivated in the previous section, factor cost shares $s_{j}$ typically represent a good approximation to related cross-price elasticities $\eta_{x_{i} p_{j}}$. This approximation is the better, the larger is the cost share $s_{i}$, regardless of whether a study is a time-series, cross-section or a panel study.

In the context of the prominent capital-energy controversy, FRONDEL and SCHMIDT (2000) provide ample empirical evidence that the issue of capital-energy complementarity is simply a matter of cost shares of capital and energy, whereas GRIFFIN and GREGORY (1976, henceforth GG76) argue that a distinction between times-series and cross-section/panel studies would reconcile the contradictory results displayed by the literature.

Before reviewing the translog studies listed in HAMERMESH (1993), for two reasons, our cost-share argument is illustrated in Table 1 by the comparison of the studies by BERNDT and WOOD (1975, henceforth BW75) and GG76. Both studies gave rise to the capital-energy controversy. First, elasticity estimates of both studies support our costshare argument most impressively. Second, apart from data on labor, BW75's data are used by BERNDT and MORRISON's (1979) study on employment effects of rising energy prices which is examined in this section, too. With respect to the capital-energy controversy, FRONDEL and SCHMIDT (2000) show that the cost share of energy E plays the major role in the determination of $\eta_{K p_{E}}$, the energy-price elasticity of capital. Because the cost share attributable to energy is typically low, estimates of any elasticity $\eta_{x_{i} p_{E}}$, specifically those of $\eta_{K p_{E}}$, may be expected to be small in absolute value.

BW75 included information on the use of materials $M$, a factor with large cost shares in any of the years during the observation period. In accordance with those large cost shares estimates of elasticities $\eta_{x_{i} p_{M}}$ are large and positive for any factor $i$ (see the left panel of Table 1), while the parameters associated with labor, $s_{L}$ and $\eta_{x_{i} p_{L}}$, take 
second place in the cost share and elasticity rankings. On the other hand, small capital and energy shares are in agreement with low estimates of capital and energy-price elasticities $\eta_{x_{i} p_{K}}$ and $\eta_{x_{i} p_{E}}$, respectively. In fact, estimates of $\eta_{K p_{E}}$ and $\eta_{E p_{K}}$ are even negative, implying BW75's conclusion of capital-energy complementarity.

Table 1: Comparison of the Studies by BW75 and GG76.

\begin{tabular}{|c|c|c|c|c|c|c|c|c|c|c|c|c|c|c|}
\hline & $\begin{array}{r}\text { B } \\
\text { Time }\end{array}$ & \multicolumn{4}{|c|}{ BERNDT \& WOOD (1975) } & & \multicolumn{7}{|c|}{ GRIFFIN \& GREGORY (1976) } & \\
\hline & 1947 & 1953 & 1959 & 1965 & 1971 & B & $\mathrm{D}$ & $\mathrm{F}$ & W-G & $\mathrm{I}$ & NL & NOR & UK & USA \\
\hline \multicolumn{6}{|c|}{ Cost Shares } & \multicolumn{9}{|c|}{ Cost Shares for 1965} \\
\hline$s_{E}$ & 0.04 & 0.04 & 0.05 & 0.04 & 0.05 & 0.17 & 0.08 & 0.11 & 0.10 & 0.15 & 0.16 & 0.17 & 0.12 & 0.13 \\
\hline$s_{K}$ & 0.05 & 0.05 & 0.06 & 0.06 & 0.05 & 0.32 & 0.37 & 0.27 & 0.39 & 0.33 & 0.32 & 0.31 & 0.26 & 0.14 \\
\hline$s_{L}$ & 0.25 & 0.27 & 0.27 & 0.28 & 0.29 & 0.51 & 0.55 & 0.62 & 0.51 & 0.52 & 0.52 & 0.52 & 0.62 & 0.73 \\
\hline$s_{M}$ & 0.66 & 0.64 & 0.62 & 0.62 & 0.61 & - & - & - & - & - & - & - & - & - \\
\hline \multicolumn{6}{|c|}{ Cross-Price Elasticities } & \multicolumn{9}{|c|}{ Cross-Price Elasticities for 1965} \\
\hline$\eta_{K p_{E}}$ & -0.14 & -0.15 & -0.14 & -0.14 & -0.16 & 0.17 & 0.08 & 0.11 & 0.10 & 0.15 & 0.16 & 0.17 & 0.12 & $0.13(0.11)$ \\
\hline$\eta_{L p_{E}}$ & 0.03 & 0.03 & 0.03 & 0.03 & 0.03 & 0.15 & 0.05 & 0.08 & 0.08 & 0.12 & 0.13 & 0.14 & 0.09 & $0.11(0.02)$ \\
\hline$\eta_{M p_{E}}$ & 0.03 & 0.04 & 0.03 & 0.03 & 0.03 & - & - & - & - & - & - & - & - & - \\
\hline$\eta_{E_{p_{K}}}$ & -0.17 & -0.17 & -0.18 & -0.18 & -0.17 & 0.32 & 0.39 & 0.27 & 0.40 & 0.33 & 0.32 & 0.33 & 0.27 & $0.15(0.14)$ \\
\hline$\eta_{L p_{K}}$ & 0.06 & 0.05 & 0.06 & 0.06 & 0.05 & 0.12 & 0.19 & 0.11 & 0.19 & 0.14 & 0.13 & 0.13 & 0.10 & $0.01(0.05)$ \\
\hline$\eta_{M p_{K}}$ & 0.03 & 0.03 & 0.03 & 0.03 & 0.02 & - & - & - & - & - & - & - & - & - \\
\hline$\eta_{E p_{L}}$ & 0.16 & 0.17 & 0.18 & 0.18 & 0.20 & 0.45 & 0.40 & 0.52 & 0.40 & 0.45 & 0.45 & 0.45 & 0.53 & $0.64(0.10)$ \\
\hline$\eta_{K p_{L}}$ & 0.26 & 0.27 & 0.28 & 0.29 & 0.30 & 0.20 & 0.29 & 0.26 & 0.26 & 0.23 & 0.22 & 0.21 & 0.25 & $0.05(0.08)$ \\
\hline$\eta_{M p_{L}}$ & 0.15 & 0.16 & 0.16 & 0.17 & 0.18 & - & - & - & - & - & - & - & - & - \\
\hline$\eta_{E p_{M}}$ & 0.49 & 0.49 & 0.47 & 0.46 & 0.46 & - & - & - & - & - & - & - & - & - \\
\hline$\eta_{K p_{M}}$ & 0.37 & 0.34 & 0.35 & 0.35 & 0.30 & - & - & - & - & - & - & - & - & - \\
\hline$\eta_{L p_{M}}$ & 0.37 & 0.37 & 0.37 & 0.37 & 0.37 & - & - & - & - & - & - & - & - & - \\
\hline
\end{tabular}

Note: B: Belgium, D: Denmark, F: France, W-G: West Germany, I: Italy, NL: Netherlands, NOR: Norway. While BW75 do not provide any standard errors, GG76 report standard errors solely for the USA. Cost shares, not reported by GG76, are calculated from reported $\mathrm{AES}_{i j}$ and $\eta_{x_{i} p_{j}}$ by the authors on the basis of (2).

The elasticity estimates of the panel study by GG76 are based on 4 observations for 9 countries. Cost shares are higher as a consequence of the omission of materials and, therefore, elasticity estimates resemble closely the pattern of cost shares: Table entries in the rows for $s_{E}$ and for estimates of $\eta_{L p_{E}}$ are very close to each other, those in the table rows for $s_{E}$ and the estimates of $\eta_{K p_{E}}$ are even identical. This implies, in particular, that capital and energy are estimated as substitutes.

In a confirmation of FRONDEL and SCHMIDT's (2000) cost-share argument, the following figures present empirical evidence for our idea that the question of estimated 
capital-skill complementarity is mainly a matter of the cost shares of capital, highskilled and low-skilled labor. The subsequent section's detailed review of empirical capital-skill studies is summarized by Figures 1 and 2, where 33 estimates of capitalprice elasticities of low-skilled and high-skilled labor, respectively, are plotted against the corresponding cost shares $s_{K}$ of capital. ${ }^{2}$

Figure 1: Empirical Evidence on the Relationship between $\hat{\eta}_{L p_{K}}$ and Cost Shares of Capital.

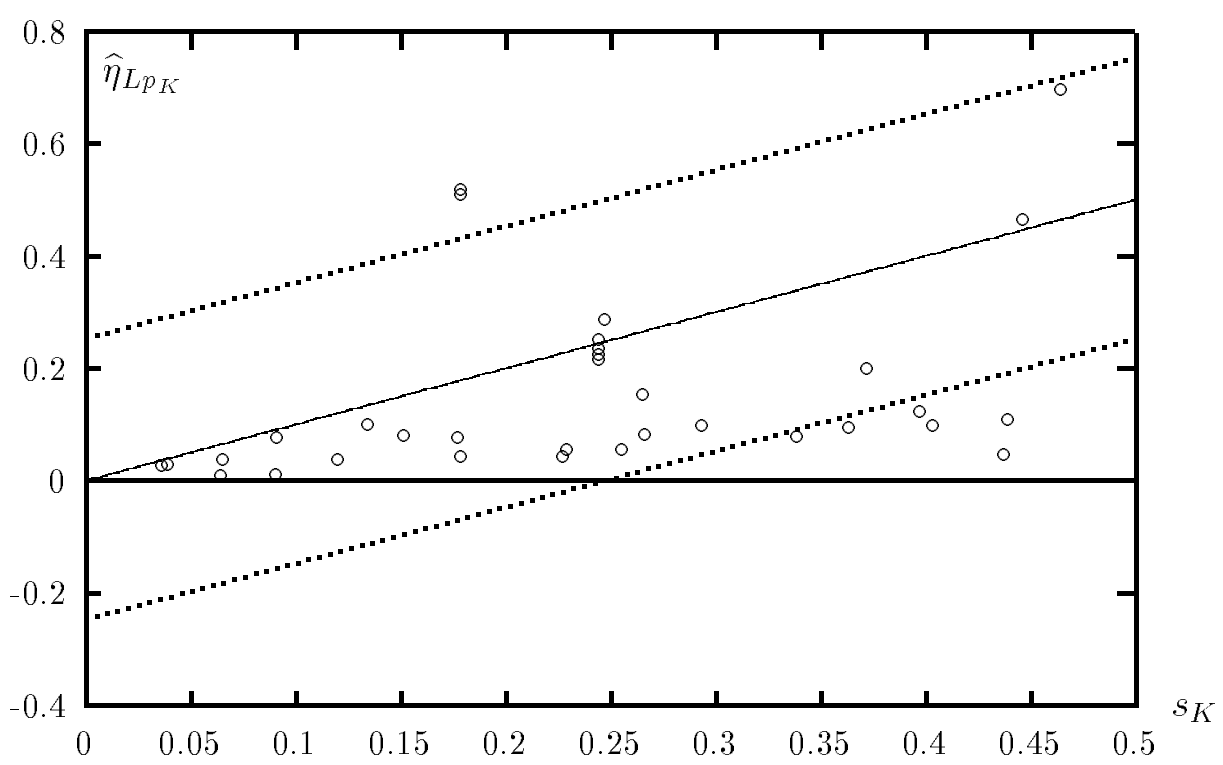

Figure 1 reveals that the overwhelming number of $\eta_{L p_{K}}$-estimates are located in an arbitrarily chosen \pm 0.25 -corridor around the benchmark given by the cost share $s_{K}$ of capital, regardless of the magnitude of the low-skilled cost shares $s_{L} .8$ out of 33 estimates display greater deviations from $s_{K}$ in absolute terms. Using the same data, each of the studies by BERNDT and CHRISTENSEN (1974) and by DENNY and FUSS (1977) provides one of these outliers. 5 outliers stem from the time-series study by BERGSTRÖM and PANAS (1992), overall providing 6 entries to Figure 1. Finally, one outlier originates from Industry 37 of PANAS' (1991) study for 16 Greek industries. PANAS' estimates

\footnotetext{
${ }^{2}$ Because of limited variation in cost shares during the sample periods, only one pair of observations is taken from each times-series study. For example, from BERNDT and CHRISTENSEN (1974) the entry $\left(s_{K}=0.18, \hat{\eta}_{L p_{K}}=0.526\right)$, originating from the last sample year, is chosen as being representative for the whole period.
} 
represent the majority of values which are not located within the 0.25 -corridor around the diagonal, reflecting the benchmark $s_{K}$. Estimates provided by all the other studies are very close to the diagonal, confirming our cost-share argument.

On the basis of the numbers given by Figure 1, for any empirical study, no matter whether a time-series, cross-section or panel study, one would expect a substantially positive estimate of $\eta_{L p_{K}}$ for relatively large capital cost shares greater than $25 \%$. In fact, albeit hardly significant, all estimates of $\eta_{L p_{K}}$ are positive in Figure 1, confirming the impression received from the literature that low-skilled labor and capital are substitutes. On the other hand, Figure 2 does not provide evidence at all for HAMERMESH and GRANT's (1979:519) sole "firm conclusion [that] phsyical and human capital are complements": Most of the estimates of the capital-price elasticities $\eta_{H p_{K}}$ seem to be positive, not always significantly, though.

Figure 2: Empirical Evidence on the Relationship between $\hat{\eta}_{H p_{K}}$ and Cost Shares of Capital.

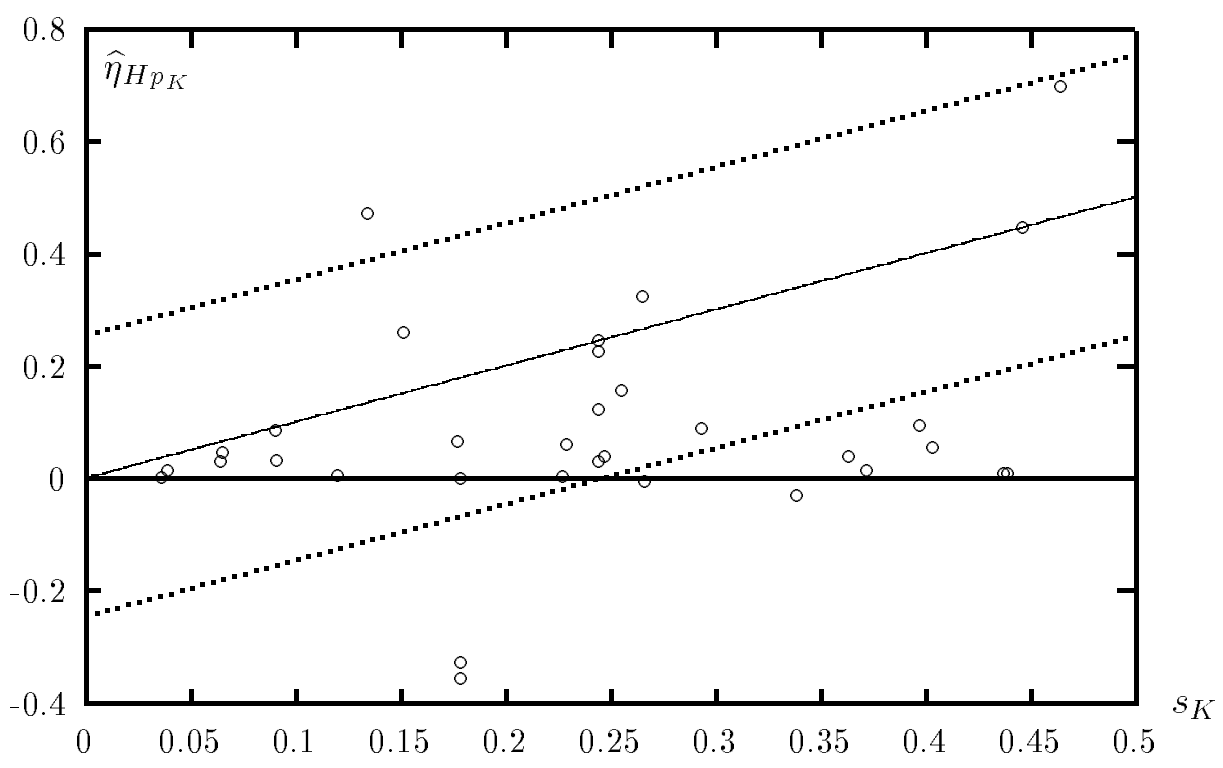

While much resembling Figure 1, Figure 2 indicates that it is again the cost share of capital $s_{K}$ which ties together the capital-price elasticity results $\hat{\eta}_{H p_{K}}$ of the translog studies summarized in HAMERMESH (1993). Both figures show that the capital-cost share $s_{K}$ represents the benchmark for both $\eta_{L p_{K}}$ and $\eta_{H p_{K}}$ estimates. This is the reason why 
complementarity of capital with either of both kinds of labor is hardly to be expected in any static translog study, in particular, if the cost share of capital is relatively large, say, more than $30 \%$. Moreover, since it is typically low-skilled labor which displays a higher cost share, there is hardly any chance to ever observe negative estimates of $\eta_{L p_{K}}$. Thus, the chosen translog specification tilts the scale in the direction of confirming the CSC-hypothesis, although it is a very questionable basis for addressing this hypothesis under any circumstance.

\section{Capital-Skill Complementarity Reviewed}

BERNDT and MORRISON's (1979, henceforth BM79) time-series study uses BW75's data on capital, energy and non-energy intermediate materials for U. S. manufacturing (19471971), but, rather than aggregating labor into a single production factor, distinguishes between two types of labor: low-skilled labor $L$ (production, non-office, or blue-collar workers) and high-skilled labor $H$ (non-production, office, or white-collar workers, which "in general ... are the more highly skilled and higher paid employees", BM79:136). Table 2 displays both cost shares and cross-price elasticities reported by BM79 for 1971 . First, comparing figures column by column shows that generally estimates of materialsprice elasticities $\eta_{x_{i} p_{M}}$ are the largest elasticities, which is in accordance with the fact that materials' cost share $s_{M}$ is by far the largest cost share.

Second, in line with our cost-share argument, estimates of the capital-price elasticities of both low- as well as high-skilled labor are quite close to the cost share $s_{K}$ of capital. Because standard errors are not provided, it remains unclear, though, whether or not the estimate classifying capital and high-skilled labor as substitutes is statistically significant. In this particular study, the estimate of the capital-price elasticity of high-skilled labor, $\hat{\eta}_{H p_{K}}=0.053$, is closer to the cost share of capital $s_{K}=0.067$ than the corresponding estimate of low-skilled labor, $\hat{\eta}_{L p_{K}}=0.044$, which seems to contradict the CSC-hypothesis. However, without any information about standard errors, this is not a firm result. Finally, the comparison of Tables 1 and 2 reveals that 
four out of six elasticity estimates concerning factors whose data are used in both studies remain unchanged after BM79's disaggregation of labor into two types, namely $\widehat{\eta}_{K p_{E}} \approx-0.16, \hat{\eta}_{E p_{K}} \approx-0.17, \hat{\eta}_{M_{p_{E}}} \approx 0.03, \hat{\eta}_{M_{p_{K}}} \approx 0.02$. By contrast, BM79's elasticity estimates concerning both types of labor do not resemble very much those of BW75's estimates in which labor is involved.

Table 2: BERNDT and MORRISON's (1979) Cost Shares and Estimates of Cross-Price Elasticities - U. S. Manufacturing 1971.

\begin{tabular}{lcccccc}
\hline \multicolumn{8}{c}{ Cross-Price Elasticities $\eta_{x_{i} p_{j}}$} & Cost Shares \\
& $x_{i}=K$ & $x_{i}=L$ & $x_{i}=H$ & $x_{i}=E$ & $x_{i}=M$ & $s_{j}$ \\
\hline$\eta_{x_{i} p_{E}}$ & -0.168 & 0.280 & -0.299 & - & 0.023 & $s_{E}=0.040$ \\
$\eta_{x_{i} p_{K}}$ & - & 0.044 & 0.053 & -0.177 & 0.013 & $s_{K}=0.067$ \\
$\eta_{x_{i} p_{L}}$ & 0.159 & - & 0.645 & 1.063 & 0.143 & $s_{L}=0.174$ \\
$\eta_{x_{i} p_{H}}$ & 0.130 & 0.441 & - & -0.777 & 0.062 & $s_{H}=0.119$ \\
$\eta_{x_{i} p_{M}}$ & 0.161 & 0.501 & 0.320 & 0.314 & - & $s_{M}=0.600$ \\
\hline \multicolumn{7}{l}{ Note: Standard errors are not reported by BERNDT and MORRISON (1979). } \\
Estimates of own-price elasticities are omitted, since those are not at issue.
\end{tabular}

Apart from the factor capital, the data base of BERNDT and CHRISTENSEN's (1974) time-series study for U. S. Manufacturing (1929-68) differs completely from those of BW75 and BM79: While Energy $E$ and intermediate materials $M$ are ignored, merely three production factors are employed in a translog production function, namely capital $(K)$, low-skilled labor $L$ (production workers), and high-skilled labor $H$ (nonproduction workers). Their estimates of both AES and cross-price elasticities display a wide range of values. This might be due to large standard errors which, unfortunately, are not reported. In fact, it is widely known in the econometric literature that elasticity estimates obtained from a cost-share system based on a translog production function are accompanied by large standard errors (see e. g. HAMERMESH and GRANT 1979:520).

As a consequence of large standard errors, estimates of capital-price elasticities for low- and high-skilled labor shown in Table 3 seem to be far away from the cost share of capital, the benchmark set by our cost-share argument. Other elasticity estimates $\hat{\eta}_{x_{i} p_{j}}$, not reported in Table 3, even seem to be more far away from the related benchmark $s_{j}$. 
The rough pattern shown by Table 3 is that estimates of $\eta_{L p_{K}}$ are uniformly higher than estimates of $\eta_{H p_{K}}$, which seem to be even negative. That is, "[n]ot only does $K$ appear to be more complementary with $[H]$ than with $[L]$ as hypothesized by ... GRILICHES, but $K$ and [ $L$ ] appear to be complements" (BERNDT and CHRISTENSEN 1974:398). This conclusion is perfectly in line with the cost shares given in Table 3, where all cost shares $s_{L}$ of low-skilled labor are much larger than the shares $s_{H}$ of high-skilled labor: According to our cost-share argument, larger shares $s_{L}$ tie elasticity estimates of $\eta_{L p_{K}}$ closer to the benchmark $s_{K}$ than it is the case for $\hat{\eta}_{H p_{K}}$ by the smaller shares $s_{H}$ of high-skilled labor.

Table 3: KLH-Time-series Studies by BERNDT and CHRISTENSEN (1974) and DENNY and FUSS (1977) for U. S. Manufacturing (1929-68).

\begin{tabular}{|c|c|c|c|c|c|c|}
\hline & 1929 & 1939 & 1949 & 1959 & 1968 & Mean \\
\hline \multicolumn{7}{|c|}{ Cost shares (own calculations) } \\
\hline$s_{K}$ & 0.173 & 0.169 & 0.159 & 0.178 & 0.180 & 0.171 \\
\hline$s_{L}$ & 0.570 & 0.589 & 0.628 & 0.546 & 0.534 & 0.572 \\
\hline$s_{H}$ & 0.257 & 0.242 & 0.213 & 0.276 & 0.286 & 0.241 \\
\hline \multicolumn{7}{|c|}{ Cross-Price Elasticities } \\
\hline \multicolumn{7}{|c|}{ BERNDT and CHRISTENSEN (1974) } \\
\hline$\eta_{L p_{K}}$ & 0.543 & 0.566 & 0.687 & 0.530 & 0.526 & 0.589 \\
\hline$\eta_{H p_{K}}$ & -0.495 & -0.443 & -1.088 & -0.392 & -0.350 & -0.628 \\
\hline \multicolumn{7}{|c|}{ DENNY and FUSS (1977) } \\
\hline$\eta_{L p_{K}}$ & 0.522 & 0.534 & 0.588 & 0.516 & 0.516 & - \\
\hline$\eta_{H p_{K}}$ & -0.458 & -0.544 & -0.825 & -0.374 & -0.322 & - \\
\hline
\end{tabular}

Using BERNDT and CHRISTENSEN's (1974) data for U. S. manufacturing (1929-68), among other things DENNY and FUSS (1977) estimate substitution possibilities among $K, L$ and $H$ on the basis of a cost-share system related to a translog production function as well, that is, with cost shares on the left-hand side and factor quantities, assumed to be exogenous, on the right-hand side. It is the estimation procedure which makes the sole difference between both studies: While BERNDT and CHRISTENSEN (1974) esti- 
mate the cost-share system obtained from a translog production function by using ten instrumental variables, DENNY and FUSS (1977) ignore possible simultaneity problems and do not employ instruments. Rather, DENNY and FUSS (1977:411) use a two-stage ZELLNER-efficient estimation procedure and find that "the different estimation procedures result in roughly identical [parameter] structures". Nevertheless, their elasticity estimates differ substantially from those of BERNDT and CHRISTENSEN (1974) in absolute terms (see Table 3 again), which might be due to large standard errors.

In a pooled cross-section time-series study for U. S. Manufacturing (1971-1977), BERGER (1984) investigates the economic consequences of increases in energy prices on the basis of a KLHE-translog approach, using data on capital $K$, low-skilled labor $L$ (production, blue-collar labor), high-skilled labor $H$ (nonproduction, white-collar labor) and energy E. For 50 states plus the District of Columbia, hence 357 (= $51 \times$ 7) observations, a common system of cost-share equations is estimated. In order to control for regional differences and industry-specific effects, regional dummies for four regions and twenty industry dummies are included, which is, of course, not necessary in BW75's study for aggregated U. S. Manufacturing.

By Table 4, our cost-share argument is confirmed again: With particular respect to the issue of capital-skill complementarity, estimates of capital-price elasticities $\eta_{x_{i} p_{K}}$ are pretty stable and closely located around the benchmark given by the cost share of capital $s_{K}$. In BERGER's study, with a relatively high cost share of capital of $s_{K}=44.8 \%$, it is not surprising at all that capital and high-skilled labor are not complements but substitutes, as are capital and low-skilled labor. Moreover, in accordance with a higher cost share of low-skilled labor relative to that of high-skilled labor, the capital-price elasticity of low-skilled labor, $\hat{\eta}_{L p_{K}}=0.471$, is closer to $s_{K}$ than the one of high-skilled labor $\left(\widehat{\eta}_{H p_{K}}=0.453\right)$, seemingly confirming the CSC-hypothesis. Yet, it is impossible to decide whether the difference between the two elasticity estimates is significant since standard errors are not provided. Finally, note that, specifically, estimates of $\eta_{K p_{j}}$ mimic the cost shares $s_{j}$ almost exactly. This is perfectly in line with our argument that a large cost share of capital reduces the weight of the first term in the expression 
$\beta_{K j} / s_{K}+s_{j}=\eta_{K p_{j}}$ and, hence, may produce elasticity estimates $\hat{\eta}_{K p_{j}}$ which are close to the other factors' cost shares $s_{j}$.

Table 4: BERGER's (1984) Study for U. S. Manufacturing (1971-1977).

\begin{tabular}{|c|c|c|c|c|c|}
\hline & \multicolumn{4}{|c|}{ Cross-Price Elasticities $\eta_{x_{i} p_{j}}$} & \multirow{2}{*}{$\begin{array}{c}\text { Cost Shares } \\
s_{j}\end{array}$} \\
\hline & $x_{i}=K$ & $x_{i}=L$ & $x_{i}=H$ & $x_{i}=E$ & \\
\hline$\eta_{x_{i} p_{E}}$ & 0.048 & -0.013 & 0.070 & - & $s_{E}=0.044$ \\
\hline$\eta_{x_{i} p_{K}}$ & - & 0.471 & 0.453 & 0.479 & $s_{K}=0.448$ \\
\hline$\eta_{x_{i p_{L}}}$ & 0.322 & - & -0.358 & -0.091 & $s_{L}=0.314$ \\
\hline$\eta_{x_{i} p_{H}}$ & 0.197 & -0.244 & - & 0.302 & $s_{H}=0.194$ \\
\hline \multicolumn{6}{|c|}{$\begin{array}{l}\text { Note: Cross-Price elasticities of factor demand are evaluated by BERGER } \\
\text { (1984) at the 1971-1977 means. Estimates of own-price elasticities are } \\
\text { omitted here, since those are not at issue. Standard errors are not } \\
\text { reported by BERGER (1984). Cost shares displayed are calculated here } \\
\text { on the basis of published information. }\end{array}$} \\
\hline
\end{tabular}

Rather than on the CSC-hypothesis, FREEMAN and MEDOFF (1982) focus on the relative inelasticity hypothesis, stating that the demand for production workers will be more inelastic in the presence of a union. Based on a 1968-1972 sample of U. S. manufacturing establishments (338 observation units in 19 two-digit industries), a KLH-translog cost function is estimated for two models, with $K$ indicating here capital, $L$ production labor, and $H$ nonproduction labor: While labor is unadjusted for quality in Model I, Model II takes labor quality into account. Within each model a KLH-translog function is estimated separately for both union and nonunion sectors (see Table 5). FREEMAN and MEDOFF (1982) find a noticeably smaller elasticity of substitution (AES) between production and nonproduction labor in the union than in the nonunion sectors. This results in a lower constant output-demand elasticity under unionism, they conclude, and, hence, confirms the relative inelasticity hypothesis.

Unfortunately, this study merely reports estimates of AES. In order to verify our cost-share argument, estimates of cross-price elasticities are calculated on the basis of information published by FREEMAN and MEDOFF (1982). In the nonunion sectors, estimates of the capital-price elasticities of both low- and high-skilled labor are statistically equal to the cost share of capital for both models (see first panel of Table 5). Both elastici- 
ty estimates scatter around the benchmark $s_{K}$, but in Model I $\hat{\eta}_{L p_{K}}$ happens to be higher than $\hat{\eta}_{H p_{K}}$, while it is vice versa in Model II. Thus, by chance, the CSC-hypothesis appears to be true for Model I, but not for Model II. However, differences between elasticity estimates are not significant for both models.

In the union sectors, only the estimates of the capital-price elasticity of low-skilled labor are very close to the cost share of capital in absolute terms (second panel of Table 5). Apparently, for high-skilled labor elasticity estimates deviate from the benchmark $s_{K}$. With large standard errors, though, differences between $\hat{\eta}_{H p_{K}}$ and $s_{K}$ are not significant in both models. Furthermore, cost shares of low-skilled labor are double the cost shares of high-skilled labor, which according to our cost-share argument may explain that capital-price elasticities of low-skilled labor are closer to $s_{K}$ than those of high-skilled labor.

Table 5: The Study by FrEEMAN and MEDOFF (1982) - U. S. Manufacturing 1972.

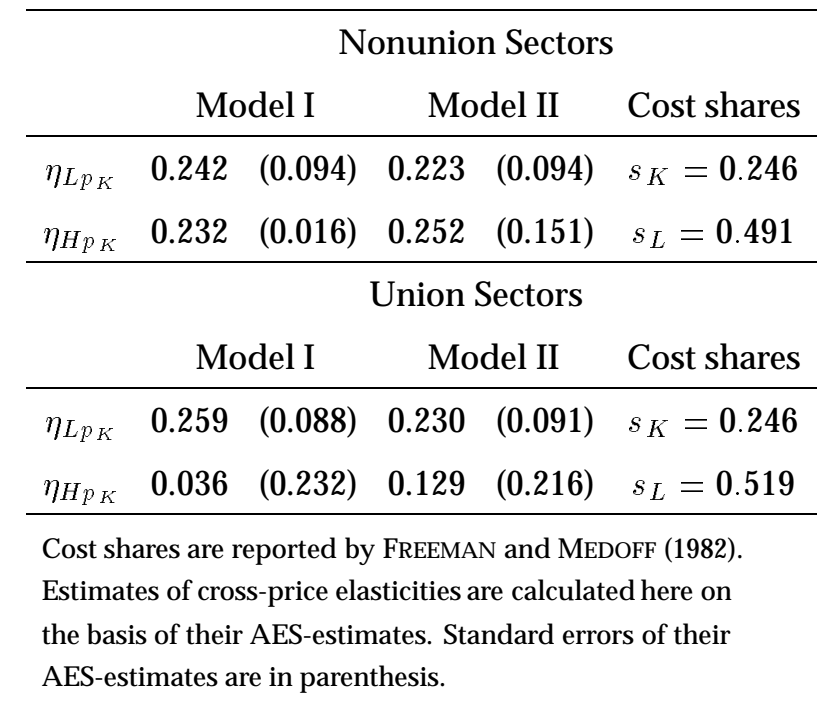

For 6 Swedish Manufacturing sectors (1963-1980), the time-series study by BERGSTRÖM and PANAS (1992) investigates how robust GRILICHES' CSC-hypothesis is. For each sector, they estimate a nonlinear-homogeneous KLH-translog cost function with non-HICKSneutral technological progress, incorporating three inputs: capital $K$, low-skilled labor $L$ (wage earners), and high-skilled labor $H$ (salaried employees). Based on this approach the authors consider 11 models by invoking various assumptions and report 
cross-price elasticities for their preferred model, which is selected by $\chi^{2}$-tests.

Table 6: KLH-Time-series Study by BERGSTRÖM and PANAS (1992) for Swedish Manufacturing (1963-1980).

\begin{tabular}{ccccccc}
\hline ISIC & Year & $\eta_{L p_{K}}$ & $\eta_{H p_{K}}$ & $s_{K}$ & $s_{H}$ & $s_{L}$ \\
\hline 31 & 1963 & 0.085 & -0.023 & 0.340 & 0.230 & 0.430 \\
& 1968 & 0.065 & -0.031 & 0.347 & 0.250 & 0.438 \\
& 1974 & 0.025 & -0.046 & 0.259 & 0.279 & 0.462 \\
& 1980 & 0.012 & -0.075 & 0.224 & 0.284 & 0.492 \\
\hline 32 & 1963 & 0.097 & 0.078 & 0.404 & 0.178 & 0.418 \\
& 1968 & 0.026 & 0.018 & 0.283 & 0.219 & 0.498 \\
& 1974 & 0.104 & 0.062 & 0.405 & 0.170 & 0.425 \\
& 1980 & 0.011 & -0.013 & 0.254 & 0.218 & 0.528 \\
\hline 34 & 1963 & 0.114 & 0.015 & 0.441 & 0.194 & 0.365 \\
& 1968 & 0.078 & 0.023 & 0.388 & 0.226 & 0.386 \\
& 1974 & 0.110 & 0.038 & 0.596 & 0.148 & 0.256 \\
& 1980 & 0.036 & 0.018 & 0.331 & 0.264 & 0.405 \\
\hline 36 & 1963 & 0.283 & -0.052 & 0.455 & 0.156 & 0.389 \\
& 1968 & 0.233 & -0.021 & 0.394 & 0.190 & 0.416 \\
& 1974 & 0.312 & 0.030 & 0.524 & 0.160 & 0.316 \\
& 1980 & 0.207 & 0.021 & 0.374 & 0.224 & 0.402 \\
\hline 37 & 1963 & 0.066 & 0.006 & 0.461 & 0.189 & 0.350 \\
& 1968 & 0.022 & -0.012 & 0.360 & 0.231 & 0.409 \\
& 1974 & 0.052 & 0.016 & 0.439 & 0.203 & 0.358 \\
& 1980 & 0.015 & -0.027 & 0.340 & 0.234 & 0.426 \\
\hline 38 & 1963 & 0.294 & 0.046 & 0.249 & 0.283 & 0.468 \\
& 1968 & 0.278 & 0.053 & 0.230 & 0.324 & 0.446 \\
& 1974 & 0.381 & 0.116 & 0.328 & 0.271 & 0.401 \\
& 1980 & 0.221 & 0.018 & 0.176 & 0.364 & 0.461 \\
\hline \multirow{2}{*}{ Note: Standard errors are not provided. } & Costshares are \\
& & & \\
& 1940 here & on the basis of published information.
\end{tabular}

This study's estimates of capital-price elasticities reflect the level given by the cost share of capital rather broadly (see Table 6). Only in industry 38 estimates of $\eta_{L p_{K}}$ and cost shares $s_{K}$ of capital are quite close in absolute terms. Yet, standard errors are not reported. So it remains unclear whether or not differences between capital-price 
elasticity estimates and cost shares of capital are significant.

Nevertheless, two crude features are observable. First, for each industry intertemporal changes in capital-price elasticity estimates $\hat{\eta}_{L p_{K}}$ are in line with intertemporal changes in cost shares of capital. Second, throughout all industries estimates of capitalprice elasticities for low-skilled labor are closer to the cost share of capital than those of high-skilled labor. Arguably, this is due to the fact that cost shares of high-skilled labor are much smaller than those of low-skilled labor in all industries as well. Indeed, all estimates of capital-price elasticities for high-skilled labor are much lower than those for low-skilled labor, which uniformly confirms the CSC-hypothesis. Moreover, BERGSTRÖM and PANAS' (1992:545) "striking result is that the CSC result was very robust to alternative specifications of the production function". The simple explanation is that, albeit specifications are varied, cost shares remain the same.

Similarly, PANAS (1991) uses time-series data for 16 two-digit Greek manufacturing industries (1958-1977) and, like BERGSTRÖM and PANAS (1992), investigates the CSChypothesis by applying a nonlinear-homogeneous KLH-translog approach with the same kind of inputs and without assuming HICKS-neutral technological progress $a$ priori. Capital-price elasticities for low- and high-skilled labor estimated by PANAS (1991) are quite close to the cost share of capital (see Table 7), or, at least, much closer to $s_{K}$ than in the study by BERGSTRÖM and PANAS (1992). Yet, standard errors are not reported, either. Thus, differences between $s_{K}$ and $\hat{\eta}_{L p_{K}}$ and $\hat{\eta}_{H p_{K}}$, respectively, might be insignificant and, hence, may not contradict our cost-share argument at all. For the industries 29,36 , and 38, in particular, $\hat{\eta}_{L p_{K}}$ and $s_{K}$ seem to be equal.

Merely for 4 industries, 24, 26, 34, and 37, capital-price elasticities of high-skilled labor appear to be substantially higher than those of low-skilled labor. To put it the other way round, the CSC-hypothesis seems to be true in 12 out of 16 industries. This result coincides with higher cost shares of low-skilled labor relative to those of high-skilled labor in all industries apart from industry 21. There, both $s_{L}$ and $s_{H}$ on the one hand and $\hat{\eta}_{L p_{K}}$ and $\hat{\eta}_{H p_{K}}$ on the other hand are pretty equal. In industry $24, \hat{\eta}_{L p_{K}}$ seems to be closer to $s_{K}$ than $\hat{\eta}_{H p_{K}}$, whereas for the industries 26,34 , and 37 , it happens that $\hat{\eta}_{H p_{K}}$ is 
higher than $\hat{\eta}_{L p_{K}}$, although $s_{L}$ is larger than $s_{K}$, and one should expect $\hat{\eta}_{L p_{K}}$ to be closer to $s_{K}$ than $\hat{\eta}_{H p_{K}}$.

Table 7: Time-Series Study by PANAS (1991) for Greek Manufacturing (1958-1977).

\begin{tabular}{lccccc}
\hline & \multicolumn{3}{c}{ Elasticities } & \multicolumn{3}{c}{ Cost Shares } \\
ISIC & $\eta_{L p_{K}}$ & $\eta_{H p_{K}}$ & $s_{K}$ & $s_{H}$ & $s_{L}$ \\
\hline 20 & 0.105 & 0.095 & 0.295 & 0.262 & 0.443 \\
21 & 0.062 & 0.067 & 0.231 & 0.417 & 0.352 \\
22 & 0.044 & 0.012 & 0.122 & 0.192 & 0.686 \\
23 & 0.050 & 0.006 & 0.180 & 0.164 & 0.656 \\
24 & 0.087 & 0.266 & 0.153 & 0.178 & 0.669 \\
25 & 0.049 & 0.011 & 0.229 & 0.126 & 0.645 \\
26 & 0.017 & 0.093 & 0.092 & 0.191 & 0.717 \\
27 & 0.102 & 0.045 & 0.365 & 0.120 & 0.515 \\
29 & 0.034 & 0.021 & 0.041 & 0.331 & 0.628 \\
31 & 0.090 & 0.002 & 0.268 & 0.175 & 0.557 \\
33 & 0.129 & 0.101 & 0.399 & 0.147 & 0.454 \\
34 & 0.061 & 0.163 & 0.257 & 0.304 & 0.439 \\
35 & 0.083 & 0.071 & 0.179 & 0.316 & 0.505 \\
36 & 0.033 & 0.008 & 0.038 & 0.380 & 0.582 \\
37 & 0.015 & 0.037 & 0.066 & 0.297 & 0.637 \\
38 & 0.084 & 0.039 & 0.093 & 0.510 & 0.397 \\
\hline Note: Cross-Price elasticities are evaluated by \\
PANAs (1991)at sample means. Standard errors \\
are not reported by PANAS (1991). Cost shares \\
are calculated here on the basis of published \\
information. & & & &
\end{tabular}

For the Australian iron and steel industry (1959-1979), TURNOVSKY and DONNELLY (1984) investigate the robustness of translog specifications with special attention to factor aggregation and separability conditions. For this reason, they estimate 6 translog approaches differing by the number of prodcution factors included. Two of those specifications are disaggregated labor models, incorporating two kinds of labor, production labor (denoted here as low-skilled labor $L$ ) and administrative labor (denoted here as high-skilled labor $H$ ): Besides $L$ and $H$, the KLHEM-model employs capital $K$, energy $E$ and materials $M$, whereas in the KLHE-model materials are omitted. Both models 
allow to examine the CSC-hypothesis. Neither on the basis of the cross-price elasticities calculated here and displayed in Table 8, nor on the the basis of the AES-estimates reported by TURNOVSKY and DONNELLY (1984), the CSC-hypothesis seems to hold for the two manufacturing sectors considered. In both models, estimates of the capital-price elasticities for high-skilled labor appear to be higher than those of low-skilled labor. Yet, once again standard errors are not reported.

Table 8: Time-Series Study by TURNOVSKY and DONNELLY (1984) for the Australian iron and steel industry (1959-1979).

\begin{tabular}{|c|c|c|c|c|}
\hline \multicolumn{5}{|c|}{ KLHEM-Model } \\
\hline \multicolumn{5}{|c|}{ Cost Shares (own calculations) } \\
\hline$s_{K}$ & $s_{L}$ & $s_{H}$ & $s_{E}$ & $s_{M}$ \\
\hline 0.136 & 0.151 & 0.048 & 0.144 & 0.521 \\
\hline \multicolumn{5}{|c|}{ Cross-Price Elasticities } \\
\hline$\eta_{H p_{K}}$ & $\eta_{L p_{K}}$ & $\eta_{K p_{H}}$ & $\eta_{K p_{L}}$ & $\eta_{E p_{K}}$ \\
\hline 0.478 & 0.108 & 0.169 & 0.0183 & 0.146 \\
\hline \multicolumn{5}{|c|}{ KLHE-Model } \\
\hline \multicolumn{5}{|c|}{ Cost Shares (own calculations) } \\
\hline$s_{K}$ & $s_{L}$ & $s_{H}$ & $s_{E}$ & \\
\hline 0.267 & 0.305 & 0.101 & 0.327 & \\
\hline \multicolumn{5}{|c|}{ Cross-Price Elasticities } \\
\hline$\eta_{H p_{K}}$ & $\eta_{L p_{K}}$ & $\eta_{K p_{H}}$ & $\eta_{K p_{L}}$ & $\eta_{E p_{K}}$ \\
\hline 0.331 & 0.160 & 0.125 & 0.183 & 0.182 \\
\hline \multicolumn{5}{|c|}{$\begin{array}{l}\text { Note: Standard errors are not reported. } \\
\text { Cross-price elasticities are caculated here } \\
\text { at sample means on the basis of published } \\
\text { information. }\end{array}$} \\
\hline
\end{tabular}

Focusing on the cost-share argument, this study's estimates of capital-price elasticities for both types of labor are in the realm of the cost share $s_{K}$ of capital: In the KLHEMmodel, the capital-price elasticity of low-skilled labor $\left(\hat{\eta}_{L p_{K}}=0.108\right)$ turns out to be closer to $s_{K}=0.136$ than that of high-skilled labor $\left(\hat{\eta}_{H p_{K}}=0.478\right)$, being in line with a cost share of low-skilled labor which is much larger than that of high-skilled labor. Yet, estimation results happen to be vice versa in the KLHE-model: $\hat{\eta}_{H p_{K}}=0.331$ is closer to $s_{K}=0.267$ than $\hat{\eta}_{L p_{K}}=0.160$. With particular respect to the capital-energy controversy, 
the energy-price elasticity of capital estimated in the KLHEM-model almost equals the cost share $s_{E}$ of energy, whereas they seem to be different in the KLHE-model. In sum, our cost-share argument is more supported by the KLHEM-model than by the KLHE-model.

\section{Conclusion}

This paper's review of the relative capital-skill complementarity hypothesis, which, "simply put, holds that physical capital is more complementary to human capital ... than to raw labour" (RICE 1989:1087), demonstrates: Using a translog approach reduces the issue of complementarity to a question of cost shares. Irrespective of all the variation in estimated coefficients, our cost-share argument is empirically relevant for all static translog studies listed in the selective summary by HAMERMESH (1993): It is the cost share of capital $s_{K}$ which represents the benchmark for both $\hat{\eta}_{L p_{K}}$ and $\hat{\eta}_{H p_{K}}$, the estimates of capital-price elasticities of low- and high-skilled labor, respectively. $\hat{\eta}_{L p_{K}}$ and $\hat{\eta}_{H p_{K}}$ scatter around this benchmark more or less due to chance. The particular data situation determines the concrete estimates via the cost shares $s_{L}$ and $s_{H}$. Thus, whether or not capital-skill complementarity is estimated to hold in an empirical study is ultimately a matter of both chance and the cost shares of high- and low-skilled labor.

A somewhat pessimistic message accompanies the straightforward cost-share argument: Static translog approaches are not as flexible as one might hope. Rather, they are limited in their ability to detect a wide range of phenomena: In a translog-world the maintained hypothesis for extracting the structural parameters from the data - the answer to the question of whether two factors are complements or substitutes would be dominated by the cost shares. For capital and energy, for example, FRONDEL and SCHMIDT (2000) show that the cost shares of capital and energy are the principal determinants in the received estimates of addressing the substitutability or complementarity of both factors. Irrespective of the particular application, the most credible way out of this dilemma might be to use micro data at the firm level, enabling the analyst to model 
the relation between factor use and price variation without resorting to a parametric functional form. Yet, in the absence of this future research this study's firm conclusion is that, in static translog studies, capital-price elasticities for both kinds of labor are mainly the result of the corresponding cost share of capital.

Even three decades after GRILICHES' original insight, we know very little about the consequences for skilled and unskilled workers that might result from shifts in the price of physical capital. In particular, it is far from clear what effects current advances in technology might have for workers of either skill. Without further evidence, all too daring conclusions on the fate of the unskilled in the "new economy" should be avoided. 


\section{References}

ApOstOlaKIS B. E. (1990): Energy-Capital-Substitutability/Complementarity. Energy Economics, Vol. 12, No. 1:48-58.

Bellmann L. , Bender S. and T. SCHANK (1999): Flexibility of Firms' Labor Demand: Substitutability or Complementarity. Jahrbücher für Nationalökonomie und Statistik. Vol. 219:109-26.

Berger M. C. (1984): Increases in Energy Prices, Costs of Production, and Plant Size. Journal of Economics and Business, Vol. 36:345-57.

Bergström V. and E. PANAS (1992): How Robust is the Capital-Skill Complementarity Hypothesis? Review of Economics and Statistics, Vol. 74:540-546.

BERNDT E. R. and L. R. CHRISTENSEN (1974): Testing for the Existence of an Aggregate Index of Labor Inputs. American Economic Review, Vol. 64:391-404.

BERNDT E. R. and D. O. WoOD (1975): Technology, Prices, and the Derived Demand for Energy. Review of Economics and Statistics, Vol. 57:259-68.

BERNDT E. R. and C. M. MORRISON (1979): Income Redistribution and Employment Effects of Rising Energy Prices. Resources and Energy, Vol. 2:131-150.

BERNDT E. R. (1991): The Practice of Econometrics: Classic and Contemporary. AddisonWesley, New York.

Blackorby C. and R. RUSSELl (1989): Will the Real Elasticity of Substitution Please Stand Up? A Comparison of the Allen/Uzawa and Morishima Elasticities. American Economic Review, Vol. 79: 882-888.

DENNY M. and M. FUSS (1977): The Use of Approximation Analysis to Test for Separability and the Existence of Consistent Aggregates. American Economic Review, Vol. 67: 404-18. 
Freeman R. B. and J. L. Medoff (1982): Substitution between Production Labor and other Inputs in Unionized and Nonunionized Manufacturing. Review of Economics and Statistics, Vol. 64:220-233.

FITZROY F. and M. FUNKE (1998): Skills, Wages and Employment in East and West Germany. Regional Studies. Vol. 32, No. 5:459-67.

Frondel M. and C. M. SCHMIDT (2000): The Capital-Energy Controversy: A Reconciliation. Discussion Paper No. 318, Department of Economics. University of Heidelberg.

GRIFFIN J. M. and P. R. GREGORY (1976): An Intercountry Translog Model of Energy Substitution Responses. American Economic Review, Vol. 66:845-858.

GRILICHES Z. (1969): Capital-Skill Complementarity. Review of Economics and Statistics, Vol. 51:465-68.

Hamermesh D. S. (1993): Labor Demand. Princeton University Press, New Jersey.

HAMERMESH D. S. and J. GRANT (1979): Econometric Studies of Labor-Labor Substitution and their Implications for Policy. Journal of Human Resources, Vol. 14:519-541.

PANAS E. (1991): Factor Substitution in Greek Manufacturing Industries: Implications for Capital-Skill Complementarity Hypothesis. Greek Economic Review, Vol. 13:71-94.

RICE G. R (1989): Capital-Skill Complementarity and the Interregional Distribution of Human Capital in U. S. Manufacturing. Applied Economics, Vol. 21:1087-1098.

SolOW J. L. (1987): The Capital-Energy Complementarity Debate Revisited. American Economic Review, Vol. 77:605-614.

TAKAYAMA A. (1985): Mathematical Economics. Second edition. Cambridge University Press, Cambridge, MA.

TURNOVSKY M. and W. DONNELlY (1984): Energy Substitution, Separability, and Technical Progress in the Australian Iron and Steel Industry. Journal of Business E Economic Statistics, Vol. 2, No. 1:54-63. 